\title{
Primary Partial Empty Sella presenting with Prepubertal Hypogonadotropic Hypogonadism: A Case Report
}

\author{
Maria Angela Matabang ${ }^{1}$ and Buena Sapang ${ }^{2}$ \\ ${ }^{1}$ Department of Internal Medicine, Ospital ng Makati, Makati City, Philippines \\ ${ }^{2}$ Department of Endocrinology, Cardinal Santos Medical Center, San Juan City, Philippines
}

\begin{abstract}
Primary partial empty sella occurs when less than $50 \%$ of an enlarged or deformed sella turcica is filled with cerebrospinal fluid in the setting of unidentified etiologic pathological conditions. Prepubertal hypogonadotropic hypogonadism presenting as its main manifestation is rare since its peak incidence commonly occurs late at 30 to 40 years of age and has a sexual predilection for female. We described a case of 20 -year-old male who presented with micropenis and absent secondary sex characteristics. Work up showed cranial MRI finding of partial empty sella, low testosterone, LH, FSH, Estradiol and Beta HCG levels. Sex hormone replacement may not improve fertility for this case but may help produce and maintain virilization and prevent future complications of hypogonadotropic hypogonadism.
\end{abstract}

Key words: PES, hypogonadotropic, hypogonadism, micropenis

\section{INTRODUCTION}

Empty sella is a radiologic finding pertaining to an enlarged or deformed sella turcica which can be partially $(<50 \%)$ or completely $(>50 \%)$ filled with cerebrospinal fluid. ${ }^{1}$ Its diagnosis is confirmed with magnetic resonance (MR) study of sellar and suprasellar regions or computed tomography (CT) for those with absolute contraindication/s to MR. ${ }^{2}$

Based on etiology, empty sella can be classified as primary or secondary. Compared to secondary empty sella which is caused by pituitary pathological conditions like previous surgical, pharmacological or radiotherapy treatment, the pathogenesis behind primary empty sella (PES) is unclear. ${ }^{2}$ Some of the identified mechanisms include incomplete formation of sellar diaphragm and the influence of suprasellar or pituitary promoting factors. ${ }^{1}$ Its incidence is not that high, ranging from $5.5 \%-12 \%$ as accidental finding in autopsy to $8 \%-35 \%$ in clinical practice. Majority of the prevalence of PES is among women - those with history of at least one completed pregnancy in their physiological history. Moreover, its occurrence in children is also less frequent compared to adults, and it is more or less associated with hypothalamic-pituitary dysfunction, genetic disorders or perinatal complication. ${ }^{2}$

\section{CASE}

RC, a 20-year-old male, sought consult in our institution for small penile size. He was born full-term via normal vaginal delivery to a 35-year-old G3P3 mother, with no perinatal complications. However, there was intake of an abortifacient (4 tablets of misoprostol) on the $5^{\text {th }}$ week of pregnancy. At birth, there was noted "monggo seed" sized penis and "paper-thin" scrotum. His mother was advised by the local health center physician to seek consult with a surgeon however due to financial difficulties, there were no tests nor consult with a specialist done. His childhood and pre-puberty years were unremarkable. There were no symptoms of palpitations, heat or cold intolerance, polyuria, polydipsia, polyphagia. There were no episodes of frequent urinary tract infection, dysuria, or abdominal pain. There were no instances of elevated blood pressure, headache, change in vision. There were no significant health problems during his childhood except for appendicitis for which he underwent an emergency appendectomy in July 28, 2008 at Ospital ng Makati.

However, at around 14 to 16 years of age, there was persistence of high pitched voice, scant pubic and axillary hair and fat deposition on waist and bilateral breasts. There was minimal growth in penile size at approximately 2-3 centimeters $(\mathrm{cm})$ and a bilateral palpable scrotal sac.

On physical examination, he was ambulatory with stable vital signs. He is overweight with BMI of $29.09 \mathrm{~kg} / \mathrm{m}^{2}$ and weight of 74.5 kilograms. His waist to hip ratio is 0.89 with his waist circumference spanning $86 \mathrm{~cm}$ and hip circumference at $96.5 \mathrm{~cm}$. He presented with eunuchoid proportion (Figure 1) with a height of $162 \mathrm{~cm}$ and arm span of $171 \mathrm{cms}$. His mother stands $151 \mathrm{~cm}$ while his father at 169
ISSN 0857-1074 (Print) | eISSN 2308-118x (Online)

Printed in the Philippines

Copyright (C) 2020 by Matabang et al.

Received: July 31, 2020. Accepted: October 19, 2020.

Published online first: November 4, 2020

https://doi.org/10.15605/jafes.035.02.11
Corresponding author: Maria Angela M. Matabang, MD

Medical Resident, Ospital ng Makati

Sampaguita corner Gumamela Streets, Pembo

Makati City, Philippines 1218

Tel. No.: +632-88826316 to 36

E-mail:mamatabang@gmail.com

ORCiD: https://orcid.org/0000-0002-5496-1216 

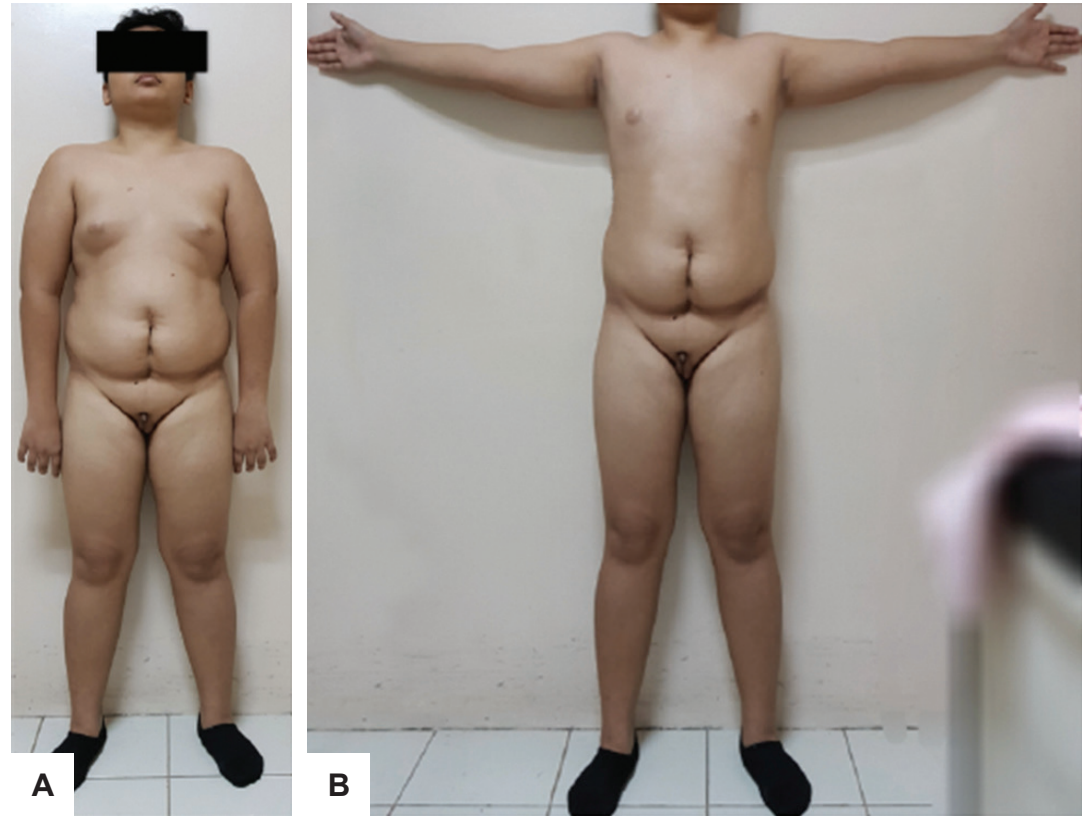

Figure 1. Eunuchoid proportion (A) height of 162 centimeters; (B) arm span of 171 centimeters.
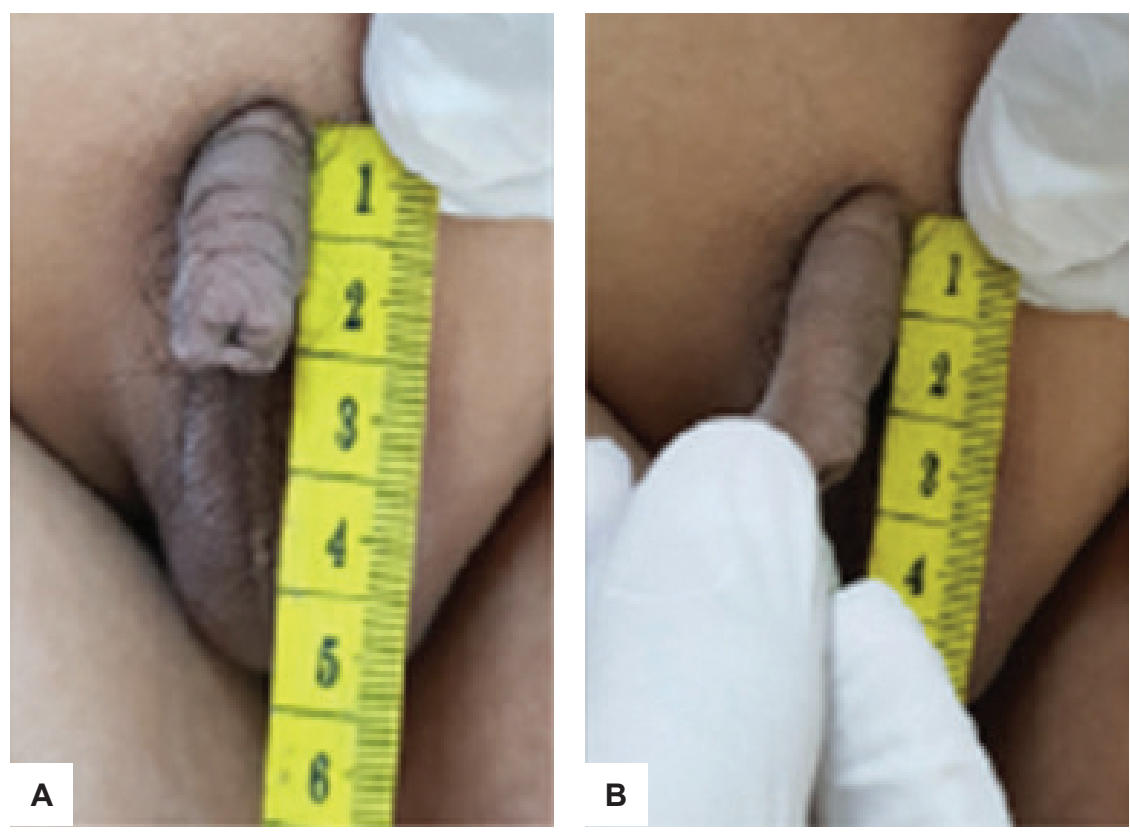

Figure 3. Tanner stage 1 (A) flaccid penile length; (B) stretched penile length; (C) penile width and scrotum.

$\mathrm{cm}$ with computed mid parental height for boys of 166.5 $\mathrm{cm}$. Thyroid gland was not palpable. He has gynecomastia without galactorrhea (Figure 2). Genital and pubic hair development was graded as Tanner Stage 1 (Figure 3). He has a flaccid and stretched penile lengths of 2.5 and $3 \mathrm{~cm}$ respectively with width of $4 \mathrm{~cm}$. He has palpable small, firm left testis while non palpable on the right. Neurologic examination was normal except for bilateral anosmia. Evaluation was done by Otorhinolaryngology service which showed recurrent rhinosinusitis. CT scan of paranasal sinuses showed pansinusitis with opacified and widened ostiomeatal units. A trial of steroid therapy was recommended which provided slight relief of anosmia.
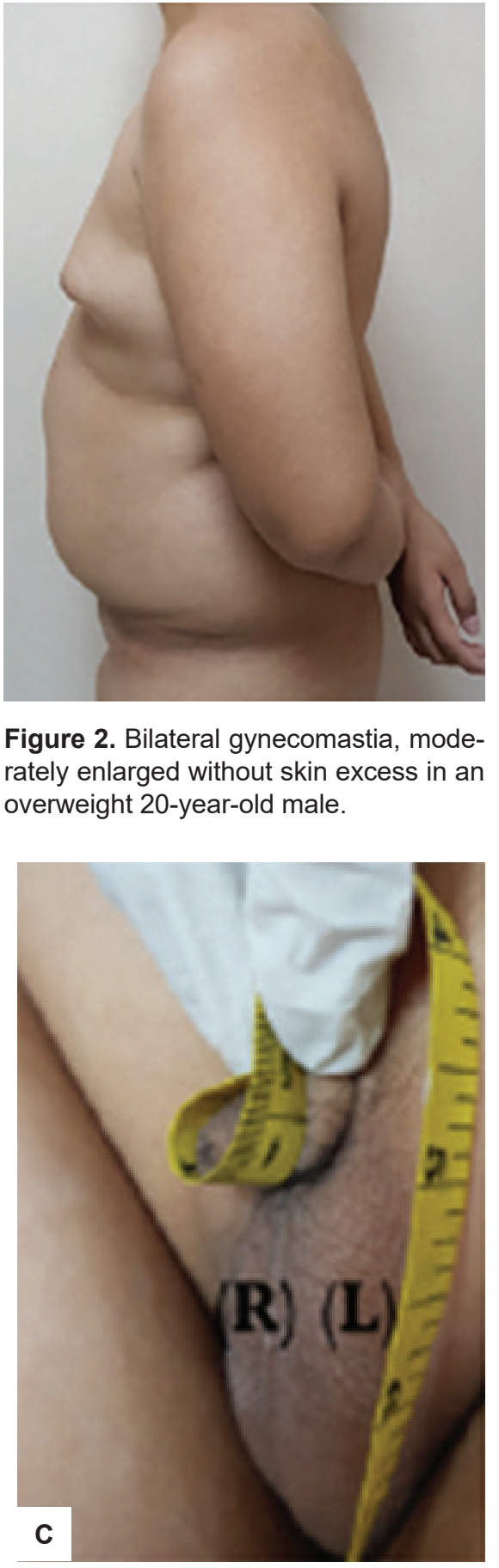

Figure 2. Bilateral gynecomastia, moderately enlarged without skin excess in an overweight 20 -year-old male.

Micropenis is defined by Schonfeld and Beebe as Stretched Penile Length (SPL) 2.5 SD less than the mean for age without the presence of any other penile anomalies and presence of internal and external genital organs compatible with a $46 \mathrm{XY}$ karyotype. $^{3}$ For an average adult patient, mean stretched penile length is $13.3 \mathrm{~cm}$ with $9.3 \mathrm{~cm}$ as the calculated 2.5 standard deviation less than the mean for age. The patient has a stretched penile length of $3 \mathrm{~cm}$ falling more than 2.5 SD below the mean for adult.

To satisfy the criteria for micropenis, pelvic and inguinoscrotal ultrasound was done to confirm the presence of internal genital organs, which revealed small left testicle measuring $0.9 \times 0.5 \times 0.7 \mathrm{~cm}$ with chronic parenchymal 

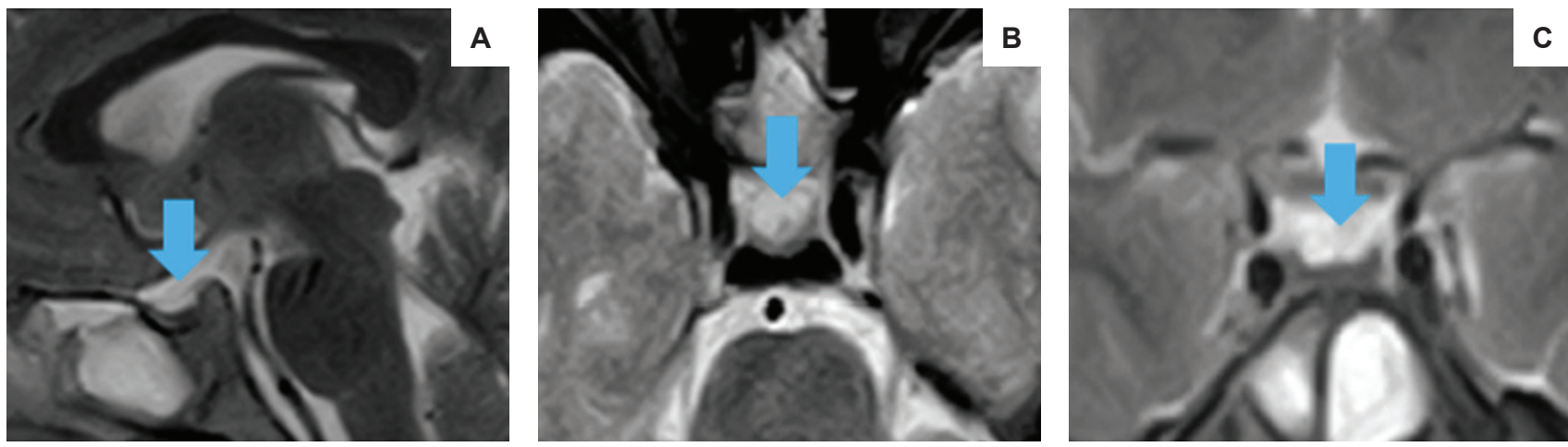

Figure 4. Cranial MRI (A) T2 sagittal view; (B) T2 axial view; (C) T2 coronal view. The arrows point to fluid-filled sella.
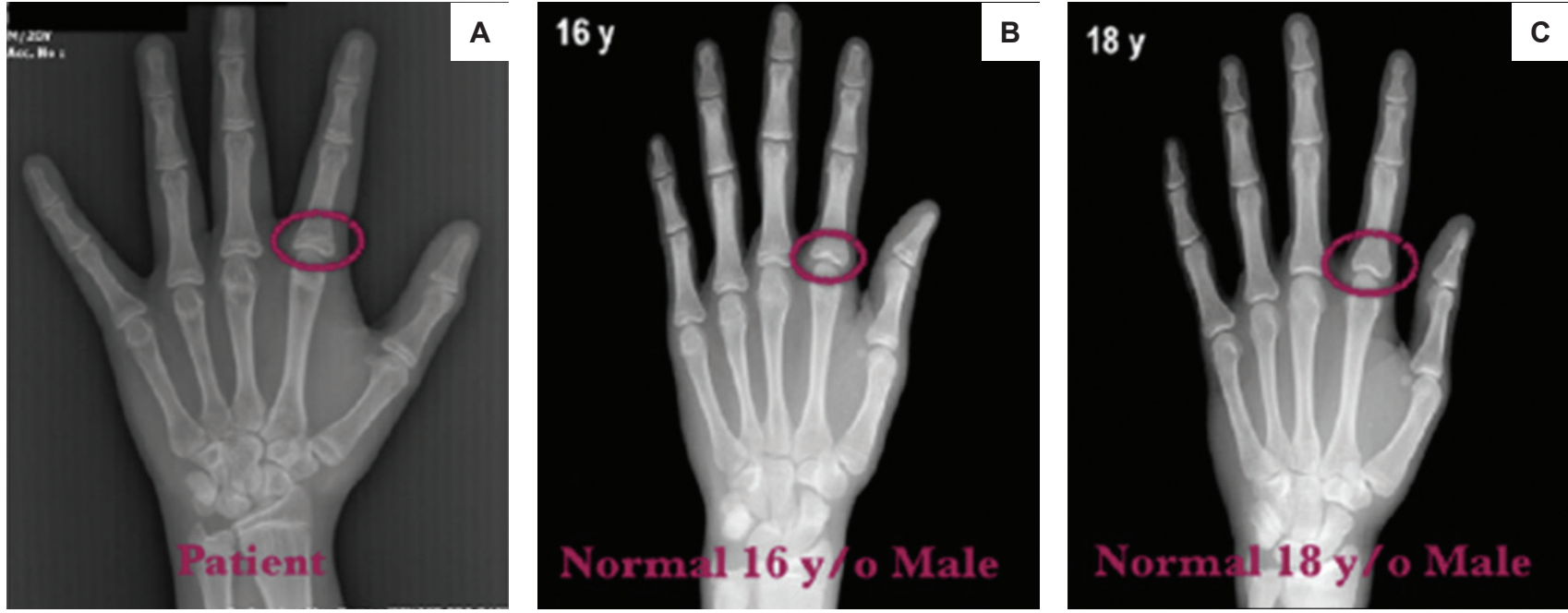

Figure 5. X-ray of left hand comparing (A) patient's bone age, (B) normal 16-year-old male and (C) normal 18-year-old male.

changes and a non visualized right testicle. The prostate gland measures $2.2 \times 1.6 \times 1.7 \mathrm{~cm}(\sim 3$ grams $)$. A whole abdominal CT scan was done with noted left inguinal hernia and ovoid soft tissue density in right inguinal region possibly representing the right testis. Other findings include hepatic steatosis and nephrocalcinosis on the left. Lastly, to satisfy the criteria, chromosome analysis was done revealing a karyotype with no numerical and structural aberrations and an $X Y$ sex chromosome complement in all 50 cells examined. Hence the patient has a male karyotype of $46, \mathrm{XY}$.

However, the patient did not just present with isolated micropenis. Alongside, he has gynecomastia, persistently high pitched voice and underdeveloped adult sexual characteristics. Most authorities accept the definition of delayed puberty as the absence of secondary sexual development at an age 2 SD above the mean age of onset of puberty. This is the age at which $95 \%$ of normal children have already entered puberty. Based on etiology, pubertal delay can be classified into constitutional growth delay or hypogonadism. The latter can be further classified into hypogonadotropic or hypergonadotropic hypogonadism. ${ }^{3}$

Though stature is the most obvious change in growth, the ratio of the upper and lower segment also changes significantly. Sex steroids are necessary for increase in growth hormone secretion and they directly stimulate epiphyseal plate's growth and fusion. In prepubertal hypogonadism, where the growth plates are not yet fused and there is lack of sex steroids, growth plates of the extremities continue to grow past the usual age of cessation. As a result, there is decreased upper to lower ratio and an increased arm span for height leading to eunuchoid proportion like in the patient.

Aside from this, determination of skeletal development by x-ray of left hand and wrist is also a useful way of establishing the stage of physiological development which in some cases may not be parallel with chronological age. The patient has a delayed bone age (compatible to 16 and $5 / 12$ to 14 and 5/12 year old male) by the Greulich-Pyle method (Figure 4). Estradiol is a product of aromatization of testosterone and it mediates additional effects of testosterone on bone resorption, epiphyseal closure, sexual desire, and fat deposition. From the physical examination and the patient's bone $\mathrm{x}$-ray, this low estradiol might have contributed to the unfused ossification centers and eunuchoid proportion. Related to this is that androstenedione is converted to testosterone by 17-beta hydroxysteroid dehydrogenase before it gets aromatized to estradiol. However, androstenedione itself can be aromatized to estrogen which might have contributed to gynecomastia and fat deposition.

The patient's cranial MRI showed a shallow sella with apparent flattening of pituitary gland at its floor (Figure 5). The results of baseline endocrine tests are summarized in 
Table 1. Serologic and immunologic test results

\begin{tabular}{lll}
\hline Test & Result & Normal Values \\
\hline Estradiol (ECLIA) & $<5.00 \mathrm{pg} / \mathrm{mL}$ & Male: $25.8-60.7 \mathrm{pg} / \mathrm{mL}$ \\
Beta HCG with Dilution & $<0.100 \mathrm{mlU} / \mathrm{mL}$ & $0.0-2.0 \mathrm{mlU} / \mathrm{mL}$ \\
FSH (ECLIA) & $0.43 \mathrm{mIU} / \mathrm{mL}$ & Male: $1.5-12.40 \mathrm{mlU} / \mathrm{mL}$ \\
LH (ECLIA) & $0.22 \mathrm{mIU} / \mathrm{mL}$ & Male: $1.7-8.60 \mathrm{mIU} / \mathrm{mL}$ \\
Testosterone (ECLIA) & $0.16 \mathrm{ng} / \mathrm{mL}$ & Male: $2.8-8.00 \mathrm{ng} / \mathrm{mL}$ \\
IGF-1 & $59.35 \mathrm{ng} / \mathrm{mL}$ & $115-350 \mathrm{mg} / \mathrm{mL}$ \\
Serum Cortisol & $160.5 \mathrm{nmol} / \mathrm{L}(8: 31 \mathrm{AM})$ & $6-10 \mathrm{AM}: 172-49 \mathrm{nmol} / \mathrm{L}$ \\
ACTH & $27.41 \mathrm{pg} / \mathrm{mL}(8: 31 \mathrm{AM})$ & $7-10$ AM: $7.2-63.30 \mathrm{pg} / \mathrm{mL}$ \\
Prolactin & $125.30 \mathrm{mIU} / \mathrm{L}$ & $86-324 \mathrm{mlU} / \mathrm{L}$ \\
FT3 & $2.95 \mathrm{pg} / \mathrm{mL}$ & $1.71-3.71 \mathrm{pg} / \mathrm{mL}$ \\
FT4 & $0.77 \mathrm{ng} / \mathrm{mL}$ & $0.70-1.48 \mathrm{ng} / \mathrm{mL}$ \\
Thyroid Stimulating Hormone & $1.0363 \mathrm{mlU} / \mathrm{L}$ & $0.35-4.94 \mathrm{ulU} / \mathrm{mL}$ \\
\hline
\end{tabular}

Table 2. Biochemical test results

\begin{tabular}{lll}
\hline Test & Result & Normal Values \\
\hline AST/SGOT & 34 & $5-35 \mathrm{U} / \mathrm{L}$ \\
ALT/SGPT & 34 & $0-55 \mathrm{U} / \mathrm{L}$ \\
BUN & 3.5 & $3.2-7.4 \mathrm{mmol} / \mathrm{L}$ \\
Creatinine & 46 & $64-104 \mathrm{umol} / \mathrm{L}$ \\
Sodium & 138 & $136-145 \mathrm{mmol} / \mathrm{L}$ \\
Potassium & 4.1 & $3.5-5.1 \mathrm{mmol} / \mathrm{L}$ \\
Chloride & 102 & $101-110 \mathrm{mmol} / \mathrm{L}$ \\
Phosphorous & 1.11 & $0.74-1.52 \mathrm{mmol} / \mathrm{L}$ \\
Magnesium & 0.91 & $0.70-0.91 \mathrm{mmol} / \mathrm{L}$ \\
HDL & 1.20 & up to $1.04 \mathrm{mmol} / \mathrm{L}$ \\
VLDL & $0.77 \mathrm{ng} / \mathrm{mL}$ & \\
Triglyceride & 0.54 & up to $1.70 \mathrm{mmol} / \mathrm{L}$ \\
LDL & 2.90 & up to $2.59 \mathrm{mmol} / \mathrm{L}$ \\
Cholesterol & 3.61 & up to $5.18 \mathrm{mmol} / \mathrm{L}$ \\
FBS & 4.78 & $3.89-5.49 \mathrm{mmol} / \mathrm{L}$ \\
\hline
\end{tabular}

Table 1 showing hypogonadotropic hypogonadism (low testosterone, FSH and LH). Other biochemical results are summarized in Table 2 which showed normal fasting blood sugar, serum sodium, potassium, AST and ALT. While, lipid profile showed normal levels of total cholesterol and triglyceride but elevated LDL.

With these findings, the patient was diagnosed with Primary Empty Sella (PES) (Partial) which is probably congenital based on history of abortifacient use on first trimester of pregnancy, findings of prepubertal hypogonadotropic hypogonadism and MRI showing a partially empty sella.

He was referred to Endocrinology and Urology services. Sex hormone replacement was recommended. He was offered testosterone therapy however this was not yet started due to lack of funds. Steroid was not initiated since serum cortisol is just borderline low and patient is also asymptomatic. Orchiectomy as prophylaxis for development of malignancy is not warranted but orchidopexy may be offered to monitor tumor development.

Counseling was offered regarding possible psychosocial impact of the physical changes brought about by the endocrine problem. Since he has a partner it was also suggested in order to help them regarding possible plans to have children. However, they refused the offer since they've already decided to adopt a child in the future. The patient verbalized that currently, the psychical changes has no derogatory impact on his personal and social life.

For continuation of care and surveillance of the possible impact of the hormonal deficiencies on other organ systems, the patient was endorsed to the succeeding endocrinology rotator and outpatient resident. He was last seen on December 2019 and repeat blood chemistries were requested; however, he was lost to follow up thereafter.

\section{DISCUSSION}

Data on epidemiology of PES varies based on means of diagnosis. It is usually an incidental finding in $5.5 \%$ $12 \%$ of autopsy cases. However, using neuroimaging, its overall incidence has been estimated at $12 \%$, while approximately $9-35 \%$ if based on clinical findings as reported in various case series. Its female-to-male ratio is 5:1 with peak incidence occurring at 30 to 40 years, occasionally earlier in women. It occurs less frequently in children and is associated with hypothalamic-pituitary dysfunction, genetic disorders or perinatal complications.

The etiology of PES is unclear but some of the etiopathogenic hypotheses identified include: 1 . incomplete formation of sellar diaphragm 2. upper sellar factors (persistent or intermittent intracranial idiopathic hypertension, CSF pulsatility, obesity, systemic hypertension) or 3. pituitary factors (conditions associated with variation of pituitary volume like pregnancy, lactation, menopause, hypophysitis, compensatory pituitary hypertrophy to primary hormonal deficit). ${ }^{2}$

Patients with PES have varied symptoms, and endocrine dysfunction is one the least common presenting manifestations. In a study done by De Marinis et al., only $19 \% \quad(n=40, N=213)$ had documented endocrine abnormalities in which only $22 \%(n=9, N=40)$ are male. ${ }^{4}$ This marginal number of male patients with PES presenting with endocrine problem was also seen in a study done by Maira et al., where in only $12 \%$ was documented. ${ }^{5}$

The prevalent endocrine problem varies in different studies. In a study done by Radha Rani et al., hypocortisolemia was most common $(62.5 \%, \mathrm{n}=10, \mathrm{~N}=16)$. In the same study, hypogonadism was observed in minority $(18.75 \%, n=3)$ which presented as amenorrhea and erectile dysfunction. ${ }^{6}$ On the other hand, in a study done by Ghatnatti et al., hyperprolactinemia was the most common dysfunction $(20.8 \% \mathrm{n}=5, \mathrm{~N}=12)$ and isolated hypogonadotropic hypogonadism was only observed in 2 patients. ${ }^{7}$

One study on PES showed hypogonadotropic hypogonadism as the most common endocrine problem $(19 \%$, $\mathrm{n}=5 ; \mathrm{N}=21$ ) which presents as oligomenorrhoea in females and decreased sexual function in male. ${ }^{8}$ Micropenis and lack of secondary sex characteristics are rare presentations since PES is seldom seen during prepubertal years. Its peak incidence is notable at postpubertal years hence the usual clinical manifestations of decrease in sexual function or erectile dysfunction are observed. One event was documented in 1973 which is almost similar with our case. A 24-year-old, 46XY patient was admitted for evaluation of infertility and lack of development of secondary sex 
characteristics. He is obese with eunuchoid proportion given the height and arm span. He has gynecomastia, bilateral undescended testes, normal prostate and decreased male body hair, however data on micropenis was not mentioned. ${ }^{9}$

The treatment for these patients entails hormonal replacement. For this case, testosterone therapy may not improve fertility at this point but it may help produce and maintain virilization and prevent future complications of hypogonadotropic hypogonadism like osteoporosis and cardiovascular problems. Lastly, semen analysis and other hormone dynamic tests are recommended to evaluate fertility potential and other possible hormonal problems respectively. ${ }^{10}$

\section{CONCLUSION}

Primary empty sella itself is a rare disease entity. Presenting as its manifestation, hypogonadotropic hypogonadism is also uncommon, mostly seen late at 30 to 40 years of age and majority in females. Prompt recognition of prepubertal hypogonadotropic hypogonadism at an early age can maximize both surgical and medical management in these patients. However, since the patient in this case sought consult late, it is also important to reiterate at this point alternative options if there are future plans for reproduction as well as methods to prevent future complications of these hormonal imbalances.

\section{Ethical Considerations}

Patient consent was obtained before submission of the manuscript.

\section{Statement of Authorship}

Both authors certified fulfillment of ICMJE authorship criteria.
Author Disclosure

Both authors declared no conflicts of interest.

Funding Source

None.

\section{References}

1. Agarwal JK, Sahay RK, Bhadada SK, Reddy VS, Agarwal NK. Empty sella syndrome. J Indian Acad Clin Med. 2001;2(3):198-202.

2. Chiloiro S, Giampietro A, Bianchi A, et al. Diagnosis of endocrine disease: Primary empty sella: A comprehensive review. Eur J Endocrinol. 2017;177(6):R275-85. PMID: 28780516. https://doi. org/10.1530/EJE-17-0505.

3. Hitapoğlu N, Kurtoğlu S. Micropenis: Etiology, diagnosis and treatment approaches. J Clin Res Pediatr Endocrinol. 2013;5(4):21723. PMID: 2437909. PMCID: PMC3890219. https://doi.org/10. 4274/ Jcrpe.1135

4. De Marinis L, Bonadonna S, Bianchi A, Maira G, Giustina A. Primary empty sella. J Clin Endocrinol Metab. 2005;90(9):5471-7. PMID: 15972577. https://doi.org/10.1210/jc.2005-0288.

5. Maira G, Anile C, Mangiola A. Primary empty sella syndrome in a series of 142 patients. J Neurosurg. 2005;103(5):831-6. PMID: 16304986. https://doi.org/10.3171/jns.2005.103.5.0831.

6. Rani PR, Maheshwari R, Reddy TSK, Prasad NR, Reddy A. Study of prevalence of endocrine abnormalities in primary empty sella. Indian J Endocrinol Metabol. 2013;17(Suppl 1):S125-6. PMID: 24251130. PMCID: PMC3830276. https://doi.org/10.4103/2230-8210.119527.

7. Ghatnatti V, Sarma D, Saikia U. Empty sella syndrome - beyond being an incidental finding. Indian J Endocrinol Metab. 2012;16(Suppl 2):S321-3. PMID: 23565413. PMCID: PMC3603061. https://doi. org/10.4103/2230-8210.104075.

8. Stelmachowska-Banaś M, Czajka-Oraniec I, Zgliczyński, W. Clinica and hormonal assessment of patients with empty sella on MRI. Postępy Nauk Medycznych. 2014;23(12):814-8. http://www.pnmedycznych.pl/ wp-content/uploads/2015/01/pnm_2014_814-818.pdf

9. Thomas Jr HM, Lufkin EG, Ellis 3rd GJ, Hartman CR, Hofeldt FD, Herman RH. Hypogonadotropism and "empty sella": Improvement in 2 cases with clomiphene citrate. Fertil Steril. 1973;24(4):252-9. PMID: 4694501. https://doi.org/10.1016/s0015-0282(16)39609-1.

10. Petak SM, Nankin HR, Spark RF, et al. American Association of Clinical Endocrinologists Medical Guidelines for clinical practice for the evaluation and treatment of hypogonadism in adult male patients--2002 update. Endocr Pract. 2002;8(6):440-56. PMID: 15260010.

Authors are required to accomplish, sign and submit scanned copies of the JAFES Author Form consisting of: (1) Authorship Certification, that authors contributed substantially to the work, that the manuscript has been read and approved by all authors, and that the requirements for authorship have been met by each author; (2) the Author Declaration, that the article represents original material that is not being considered for publication or has not been published or accepted for publication elsewhere, that the article does not infringe or violate any copyrights or intellectual property rights, and that no references have been made to predatory/ suspected predatory journals; (3) the Author Contribution Disclosure, which lists the specific contributions of authors; and (4) the Author Publishing Agreement which retains author copyright, grants publishing and distribution rights to JAFES, and allows JAFES to apply and enforce an Attribution-Non-Commercial Creative Commons user license. Authors are also required to accomplish, sign, and submit the signed ICMJE form for Disclosure of Potential Conflicts of Interest. For original articles, authors are required to submit a scanned copy of the Ethics Review Approval of their research as well as registration in trial registries as appropriate. For manuscripts reporting data from studies involving animals, authors are required to submit a scanned copy of the Institutional Animal Care and Use Committee approval. For Case Reports or Series, and Images in Endocrinology, consent forms, are required for the publication of information about patients; otherwise, appropriate ethical clearance has been obtained from the institutional review board. Articles and any other material published in the JAFES represent the work of the author(s) and should not be construed to reflect the opinions of the Editors or the Publisher.

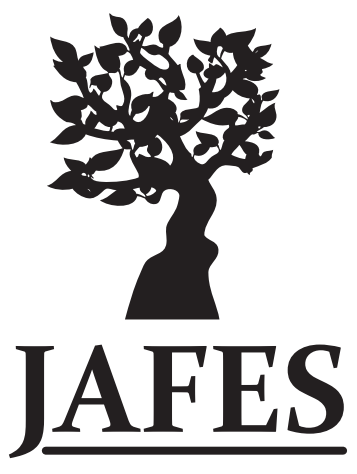

\section{Had an intriguing discussion in Grand Rounds? Share your Clinical Case Seminars at} JAFES@Asia.com. 